Review Article

\title{
Is Man the New Prospective Amplifying Host? Evolving Faces of SARS-CoV Dynamics and the Epidemiological Challenges
}

\author{
Ritwika Chatterjee', Sajal Bhattacharya ${ }^{2}$, Rina Tilak ${ }^{3}$ \\ ${ }^{1}$ Research Student, ${ }^{2}$ Professor (Associate), Postgraduate Department of Zoology, Asutosh College (University of Calcutta), \\ Kolkata, West Bengal, India. \\ ${ }^{3}$ Scientist 'G', Department of Community Medicine, Armed Forces Medical College, Pune, Maharashtra, India. \\ DOI: https://doi.org/10.24321/0019.5138.202131
}

\section{I $\quad \mathbf{N} \quad \mathbf{F} \quad \mathbf{O}$}

\section{Corresponding Author:}

Rina Tilak, Department of Community Medicine, Armed Forces Medical College, Pune, Maharashtra, India.

E-mail Id:

rinatilak@hotmail.com

Orcid Id:

https://orcid.org/0000-0003-3781-0210

How to cite this article:

Chatterjee R, Bhattacharya S, Tilak R. Is Man the New Prospective Amplifying Host? Evolving Faces of SARS-CoV Dynamics and the Epidemiological Challenges. J Commun Dis. 2021; 53(2): 89-99.

Date of Submission: 2021-06-04

Date of Acceptance: 2021-06-10

\section{$\begin{array}{lllllllllll}\mathbf{A} & \mathbf{B} & \mathbf{S} & \mathbf{T} & \mathbf{R} & \mathbf{A} & \mathbf{C} & \mathbf{T}\end{array}$}

Introduction: The ongoing COVID-19 pandemic has wreaked havoc across the globe. Health systems are grappling with an unprecedented pressure, as the highly virulent SARS-CoV-2 strain is spreading unhinged, under a yet to be understood selection pressure. To understand the underlying causes, and the rapidly evolving disease epidemiology, we need to look closely and comprehend the evolutionary dynamics of the Human Coronaviruses or the HCoV.

Methods: The research about this narrative review was conducted using digital platforms like PubMed/Medline, Semantic Scholar, medXiriv, Google Scholars, NIH, EMBL repository, John Hopkins CSSE COVID-19 Data, ResearchGate, and all the mentioned published work, peerreviewed research articles, and data, have been accessed using the same.

Results: The global rise in COVID-19 incidence and the declining trend witnessed in CFR clearly indicates rapid adaptability of the virus across a widespread population encompassing varied genetic make-up, race, diversity, and others. The last two decades have witnessed two HCoV related epidemics viz. the highly pathogenic Severe Acute Respiratory Syndrome Coronavirus or SARS-CoV and MERS-CoV. While both instances reflect the suspected role of bats as the common reservoir host, the differing intermediate hosts and subsequent spill over to humans is alarming.

Conclusions: Through this review, we hypothesise that large-scale pandemics such as this, with alarming instances of differential case incidence patterns in widely varied climatic and geographical conditions put forth the rapid genetic adaptability of coronaviruses. This raises further concerns of a prospective "amplifying-host" in man keeping in mind the widely prevalent asymptomatic silent carriers of COVID-19 currently present across the globe.

Keywords: Amplifying Host, COVID-19, SARS-CoV-2, Selection Pressure, Zoonotic Diseases 


\section{Introduction}

The human coronaviruses (HCoVs) are positive-sense, non-segmented, single-stranded RNA viruses, with seven different strains including the most recent Severe Acute Respiratory Syndrome Coronavirus 2 (SARS-CoV-2). Since their first identification in the mid-1960s, they have been best known as the causative agent of common cold and flu. It is, however, perplexing as to how exactly these human coronaviruses of animal origin, went from causing mild upper respiratory tract infections as in HCoV-229E, HCoV-OC43, $\mathrm{HCOV}-\mathrm{NL63}$ and HCoV-HKU1, to progressively severe disease epidemiology as in the first SARS-CoV and Middle East Respiratory Syndrome Coronavirus (MERS-CoV) outbreaks of 2002 and 2012, respectively. ${ }^{1,2}$ Both SARS-CoV and MERSCoV, and the HCoV-NL63 as well as HCoV-229E have most likely originated in bats, while HCOV-OC43 and HCoV-HKU1 have their suspected origin in rodents. ${ }^{3}$

In fact, $80 \%$ of the viruses that are known to affect humans propagate within natural reservoir hosts such as pigs, cattle, poultry animals, bats, birds, and arthropods. When, in some cases, through the process of zoonosis, these viruses spillover to human hosts, the result can be described as exactly what we are facing now: an outbreak. ${ }^{4,5}$

In the process of viruses adapting to the human population, mutations in the viral genome, re-assortment as well as genetic recombination events between the virus and host, could be the critical factors. ${ }^{6,7}$

It is significant to note that a majority of alpha-coronaviruses and beta-coronaviruses were identified in bats, and many coronaviruses phylogenetically related to SARS-CoV and MERS-CoV were also discovered in diverse bat species. ${ }^{8,9}$ This clearly points out the probable sequential mutation events and recombination of bat coronaviruses, which further changed during the spillover to intermediate hosts, and finally acquired the ability to infect human hosts. The question now is that with a largely asymptomatic host range within a single species, is it possible to have undetected "mutation mist" of a yet to emerge, silent reservoir host? To be precise, is it possible, that the current widespread infection within the human species, with a huge bulk of asymptomatic cases, might serve as a perfect working ground for even more species-specific interaction at the genomic or epigenomic level? Answering this question would need extensive evaluation on how the evolution of coronaviruses from a strictly zoonotic origin gradually blurred the species barrier to a quickly progressing intra-specific viral-host range. This review looks into the evolutionary significance of the coronavirus and the subsequent epidemiological challenges faced by public health systems due to its rapid global emergence.

\section{Methods}

The research was conducted using digital platforms like PubMed/Medline, Semantic Scholar, medXiriv, Wiley Online Library, Google Scholars, NIH, EMBL repository, John Hopkins CSSE COVID-19 Data, ResearchGate, and all the mentioned published work, peer-reviewed research articles, data, have been accessed using the same. Both peer-reviewed and non-peer-reviewed publications have been searched and used, with the medium of language used being English. All the mentioned databases include a wide variety of disciplines allied to coronaviruses, zoonotic diseases, spillover theories, host ranges, viral evolution and adaptability, mutations, bats, and ecological balance.

Initially, the search was conducted using PubMed with Medical Subject Headings (MeSH) terms such as, "human coronaviruses,' 'SARS-CoV,' 'coronavirus evolution,' 'zoonosis,' 'impact of climate change on zoonotic disease spread,' 'mutation in coronaviruses,' 'RNA viruses,' by different combinations. After this step, relevant keywords searchable in the article titles and/ or abstracts were added to expand the search domain. For all other databases, the same approach was followed. Additionally, through Google Scholar, other relevant articles were reviewed with respect to the topic.

The data for case incidences and deaths for calculation of Case Fatality rate were collected from the John Hopkins CSSE COVID-19 Data (accessed on30 Apr 2021).

The findings, observations, hypothesis, and comments made in this review regarding the mentioned topic are based on published work as listed under the reference section.

\section{Result}

\section{A Brief Analysis of Ongoing COVID- 19 Pandemic Data from 0 I Mar 2020 to 30 April 202 I}

The COVID-19 pandemic data in Figures 1 and 2 indicate an increasing number of cases and a declining trend in Case Fatality Rate (CFR) from 01 March 2020 to 30 Apr 2021, the date of last access. This could be attributed to the fact that testing across the world is taking place at a faster pace bringing down the CFR with increased cumulative case incidence, thereby indicating the rapid adaptability of the virus across a widespread population encompassing varied genetic make-up, race, diversity, and others.

In the following sections, the rapid turn of this COVID-19 outbreak into a pandemic with an unprecedented epidemiological challenge will be evaluated along with all the associated aspects of the SARS-CoV- 2 virus, in the light of evolution and the events that might have led to the crossing of species barrier from a zoonotic origin. 


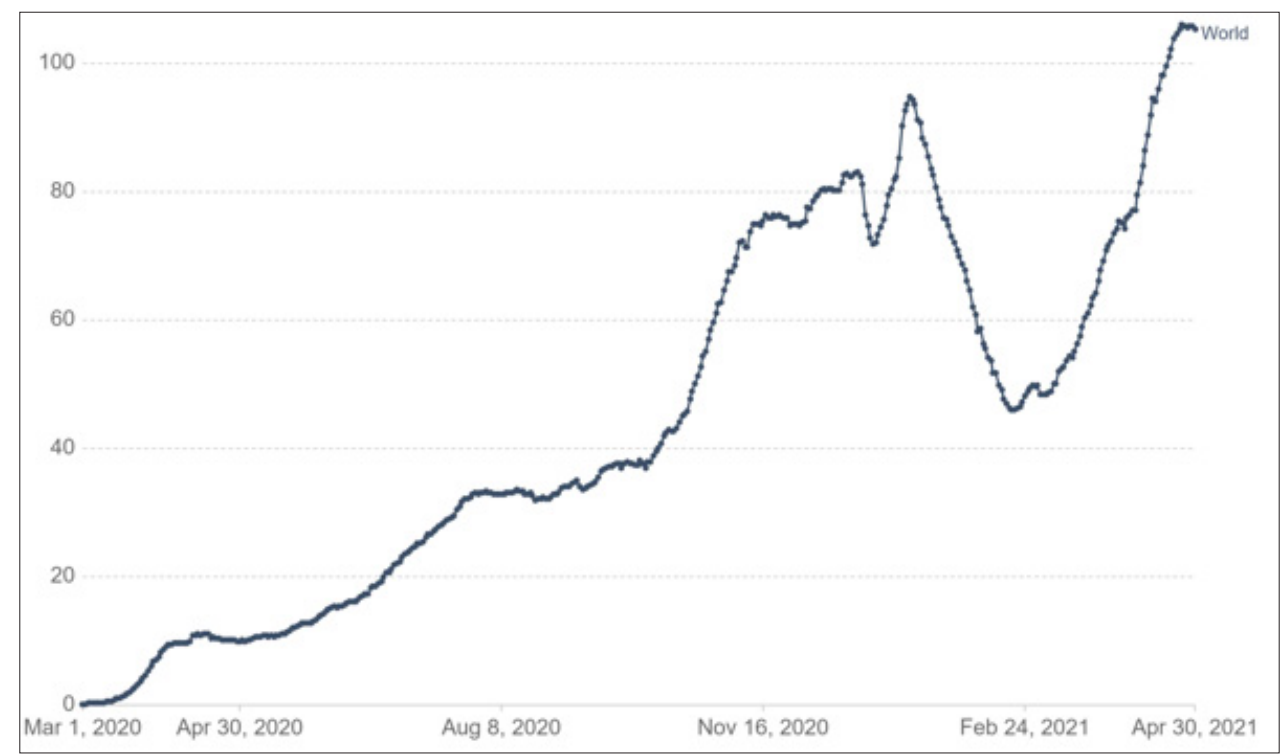

Figure I.Global Daily New Confirmed COVID - I 9 Cases per million People from 0 I March 2020 to 30 April $2021^{10}$

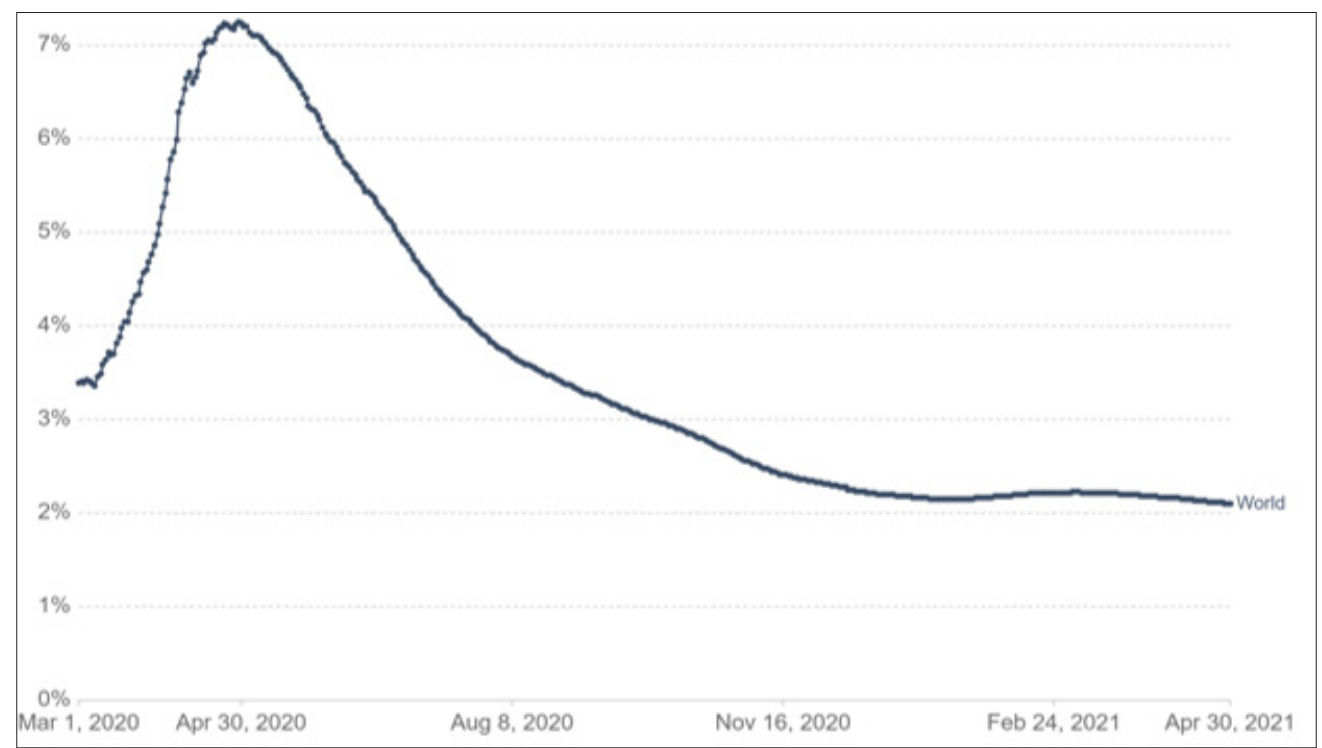

Figure 2.Global Case Fatality Rate of COVID-I 9 Pandemic from 0 I March 2020 to 30 April 202 I $^{\prime \prime}$

* The Case Fatality Rate (CFR) is the ratio between confirmed deaths and confirmed cases

\section{The Epidemiological Face of Recent Coronavirus}

The current strain of coronavirus causing the global pandemic of COVID-19, SARS-CoV-2, is a member of a family of viruses that cause lower respiratory tract infections, pneumonia, fever, breathing difficulty, as well as lung infection. ${ }^{12-17}$ Although present in a wide variety of animal reservoir hosts, instances of crossing the species barrier to humans, is rare. The outbreak began with Wuhan as the epicentre, in December 2019, when patients with lower respiratory tract infections and an unknown form of pneumonia started getting admitted to hospitals. ${ }^{18}$ The patient zero and the initial cluster of COVID-19 have been linked to the wet markets of Hubei province where the first instances of spillover of the zoonotic origin virus are suspected to have taken place. ${ }^{18-20}$ But how this strain garnered such potency in a new host range is a matter of deep concern. To evaluate the current epidemiological challenge, we need to analyse the spillover event and its probable underlying roots in the light of evolution as well as the history of previous outbreaks in the last two decades.

\section{Coronavirus and Evolving Adaptability}

Molecular analysis of several families of viruses responsible for dengue, Zika, COVID, Human Papilloma virus (HPV) infection, Human Immunodeficiency Virus (HIV) and others have shed some light on the nature of specificity and preciseness that is involved in the viral replication process among different host species. For a successful replication 
event to happen within a potential host cell, a multitude of protein-protein interactions must be in place. ${ }^{21-22}$

Recent data from genomic analysis suggests that in the current pandemic, extensive levels of transmission of the SARS-CoV-2 across divergent populations globally have led to a large section of identified genetic diversity and subsequent clades in action. ${ }^{23}$ While several regions of the SARS-CoV-2 strain have been shown to retain conserved sequences, others have accumulated significant diversification. ${ }^{24}$ Homoplastic events due to recurrent mutations specifically those leading to non-synonymous changes in the amino acid sequences and concurrently the proteins involved, hint at the still-adapting virus to its new host range: humans. It is known that one of the hallmarks of SARS$\mathrm{CoV}$ replication-transcription activities is the expression of genomic RNA in the open-reading frame 1a (ORF1a) and ORF1b, which code for the necessary protein factors. Three sites identified in Orf1ab in the regions that encode Nsp6, Nsp11, Nsp13, including one in the Spike protein have been found to be regions of recurrent mutation events. These further highlight the underlying evolutionary trends that set the coronavirus towards a higher level of human-host adaptation. ${ }^{25}$

\section{Role of S Proteins in Viral Adaptability}

The Spike or S protein is an important structural component of coronavirus. It is intrinsically involved in the binding of the virus to the host receptor as well as processing of the viral entry complex. For several mammalian and avian variants of the coronavirus, the S protein is cleaved into S1 and S2. ${ }^{26}$ While the S1 is involved in the attachment process, S2 plays a role in fusion. ${ }^{26}$ The high divergence rich S1 contains a receptor-binding domain (RBD) and the more conserved S2 subunit contains two heptad repeat (HR) domains. These two domains, especially the RBD, have a critical role in adaptability towards human angiotensin-converting enzyme 2 (ACE2). ${ }^{27}$ Studies have shown that a base alteration that changes residue 479 to asparagine and 487 to threonine, is a positively selected site-directed mutagenesis that aids in RBD-ACE2interactions. ${ }^{27,28}$ However, this is just one instance of sequence change events that are capable of tinkering with the nuances of changing viral adaptability. ${ }^{29-33}$

\section{Adaptability Constraints}

A fine balance between optimum utilisation of beneficial host protein reservoir and "host-immune-action" escape must be maintained for successful host selection and subsequent survival. It should be noted at this point that the evolutionary selection process for viruses with a greater ability to adapt rapidly to new hosts also favours the coselection of those deemed more effective at intraspecies transmission in the new host. ${ }^{34-37}$ This rapid adaptability constraint comprises two main factors: i) the ability of the virus to interact with the host surface protein associated with its concerned niche, and ii) the scope of transmission among the new host species. ${ }^{36,38}$

\section{Overcoming Constraints and Role of Viral Dynamics}

For the first factor mentioned above, similarity of the primary sequence at the interface of the virus-host interactome plays the most vital role. This can be illustrated well through the SARS-COV-2 interaction dynamics, recently identified in humans. The human angiotensin-converting enzyme 2 (ACE2), is a protein that is found on the outer cell membranes of lungs, arteries, heart, kidney, and intestines. ${ }^{39,40}$ Sequence homology data has revealed that this ACE2 protein serves as a functional receptor for the spike glycoprotein of the human coronavirus HCoV-NL63, SARS-CoV, and SARS-CoV-2. ${ }^{40-41}$ As already mentioned, animal reservoirs in nature harbour many viral strains.15 However, most of them do not pose a threat to human population due to the species barrier ensured by the non-equivalent nature of interfaces of virus interaction among different species. Moreover, the evolving nature of host cell receptor proteins also acts as a potential block to rampant host-switching events. ${ }^{15,42-44}$

But alarmingly, some bat CoVs have acquired an evolved spike protein (S protein) variant that can interact with the human ACE2. In fact, spike protein variants, capable of ACE2 compatibility have also been found in the randomly sampled bat population. ${ }^{45,46}$ Apart from $S$ protein which is definitely an important determinant of viral tropism and host spectrum ranges, other viral protein-encoding genes like ORF8, can undergo mutations within new hosts and increase the range of receptor-recognition domains. ${ }^{45-49}$ This could be attributed to high viral plasticity at the genomic level.

Usually, for the vast majority of viruses found in nature, overcoming the constraints of adapting a perfect mutational mist that aids in successful and enhancing receptor-mediated host interactions is a rare chance factor. ${ }^{46}$ But, in these rare occasions, in some viruses like in the case of SARS-CoV, fewer mutational combinations might be potent enough to create alive-on-arrival viral variants that can begin replicating upon encountering a human host.

The working bench of such positively selected mutation events might be the animal reservoir or an intermediate host species or even "silent-carrier-populations" nurturing the circulating viral load. ${ }^{50}$ However, in the evolutionary perspective, it is essential to keep an open mind that these mutational combinations must have arisen without the advantage of being specifically targeted for selection within the human body. This is because selection can only occur after replication in humans has begun and also, most importantly, evolution is the operational tool that favours selection of an easily spreading strain. ${ }^{51,52}$

This brings to focus the second factor mentioned in the 
context of virus adaptivity i.e. the scope of transmission within new host species. Mutation prone RNA-viruses have higher chances of evolutionarily significant adaptive selection, thus setting the stage for cross-species transmission. ${ }^{53,54}$ But this brings us to an important question, the virus as evident from current data, is still undergoing mutations and though the positive selection of those that increase their survival benefits are favourable, high levels of random mutation events are detrimental for their adaptation in the long run in the context of evolution. It could be hypothesised at this point that a larger selection pressure is at play. Reservoir hosts such as bats have been threatened due to a largely disturbed ecological balance by anthropogenic activities which in turn have set into motion an unprecedented selection pressure favouring random mutations and subsequent host-switching events. ${ }^{55}$

\section{The Human Coronavirus Spillover Event}

The emergence of SARS-CoV in the human population is a classic example of an RNA virus utilising its molecular capabilities to alter its host range. ${ }^{7}$ The bat-related coronaviruses show great genetic diversity ${ }^{56}$ and are also one of the oldest known coronaviruses isolated from other animal species. The SARS-CoV is suspected to have originated through recombination events within the bat SARS-related coronaviruses. ${ }^{57}$ It is further hypothesised that the recombinant virus-infected civets and humans and then adapted to these hosts before causing the SARS epidemic. MERS-CoV likely spilled over from bats to dromedary camels at least three decades ago and since then has been prevalent in dromedary camels. ${ }^{58} \mathrm{HCoV}-229 \mathrm{E}$ and HCoV-NL63 usually cause mild infections in immunocompetent humans ${ }^{58,59}$ and their progenitors have recently been isolated in African bats. While the camelids are likely the intermediate hosts of HCoV-229E, HCoV-OC43, and HKU1, all being mainly harmless in humans, have most likely originated in rodents. ${ }^{1}$

Preliminary studies of phylogenetic history suggest that there could be an involvement of ancient recombination events that occurred between bat SARS-like-CoV and the ancestor of SARS-CoV, which propelled the bat SARSlike-CoV adaption amongst civets and humans. ${ }^{60,61}$ The current SARS-CoV-2 strain bears a $96 \%$ similarity to a bat coronavirus strain Bat-CoV-RaTG13, although there is a lack of direct evidence to suggest bats as the origin of spillover to humans. ${ }^{62}$ Moreover, sequence similarity within the $\mathrm{S}$ protein has also been found between SARS-CoV-2 and that of Bat-CoV-ZXC21 and Bat-CoV-ZC45. ${ }^{62,63}$ But as with SARS-CoV and MERS-CoV, it is hypothesised that in the current outbreak, an intermediate host is at play. As for what exactly this intermediate host is, there is still not enough data to assert that. However, some studies have shown that the S protein in SARS-CoV-2 bears similarity to a pangolin-CoV, although the sequence similarity is closer to bats. ${ }^{12}$ This further shows how the CoV has mutated into highly adaptable strains in not one but multiple hosts across different species. The exact sequence of the spillover event that led to this pandemic is still debatable, but these data do shed some light and give some tangible hints about the multispecies-involving complex route of this virus.

\section{Discussion}

Rapid globalisation, rampant encroachment of forest areas, exploitation of wildlife, and rising temperature levels due to global warming, have changed the ecological homeostasis of Earth, drastically. ${ }^{64}$ Viruses have been an intrinsic part of nature since billions of years, and many animals including mammals have served as their reservoir hosts. With appropriate blocks of species barrier and selective protein-based interactome differences among the species, the chances of random spillover events were negligibly low. However, disturbances, in the natural homeostasis (due to factors mentioned above), has blurred the lines of host-range expansion among the viruses. Human-tohuman transmission of viruses with high host plasticity is dangerously facilitated by increased contact between taxonomically diverse animal hosts, through events such as domestication, wildlife kept in similar confined circumstances or those sold in wet markets. ${ }^{5,65}$

From 2002 to 2020, the incidences of SARS, MERS, and Avian flu epidemics have increased dramatically. As demonstrated in earlier outbreaks, as well as in the current COVID-19 pandemic, the adaptivity of these zoonotic viruses is surpassing not only species barrier, but also vastly different geographical, climatic, and other endogenous factors involved in viral tropism. ${ }^{66,67}$

The above data clearly suggests that a larger driving force is at play when it comes to SARS-CoV-2. It can be hypothesised that this Coronavirus was impacted with a threat of shrinking host range in the animal reservoir. The exact reason behind this, although debatable, could be extreme selection pressure faced at the interface of a dwindling number of most critical of its reservoir host, changing climatic factors propagating negative selection within recognised hosts or other unprecedented challenges developing over a course of the last two decades. ${ }^{68}$

Moreover, as mentioned earlier, evolutionary forces at play impact viruses towards increased spread that is equivalent to a higher survival value of a species. Based on this logic, it can be surmised that when a viral population co-evolving within a reservoir host suddenly reaches a bottleneck, the chances of spillover events theoretically increase.

Mutations in the viral genome, genetic re-assortment as well as recombination events between the virus and host, could be critical factors. ${ }^{69,70}$ In SARS-CoVs, mutations leading to positive selection of favourable changes have 
happened at unfathomably faster rates compared to evolutionary time scales required for natural selection to act on a change, although this could be attributed to the fact that RNA viruses have a higher degree of mutation rates. ${ }^{71,72}$ Introduction to new host encompassing suspected intermediate or amplifying hosts or yet to be identified "mixing pots" could have played a role in this context. ${ }^{67}$ The species barrier jump to a new host and subsequent human to human transmissions of SARS-CoV-2 is notable. The disease has progressed aggressively yet with wideranging differences in manifestations in a global distribution. This led to the concept of virus "mutation mist", which involves a wide spectrum of mutated virus strains; those are yet to be selected in nature for spreading and infection. This "mutation mist" could be the result of the virus-host interaction. Different reported clades of SARS-CoV-2 for COVID-19 may be the result of positive selection of the strains from the virus "mutation mist".

This hypothesis may further be supported by the fact that the disease has progressed aggressively yet with wide ranging differences in manifestations in a global distribution. It is already clear that although the species barrier jump to new host and subsequent human to human transmissions at this scale is new but the dynamic nature of human coronaviruses has been evident for long.

Human population has reached 7 billion at an alarmingly fast rate and this has led to increased interspecies interaction, owing to interferences. Adding to this burden, the increased global interaction at an intraspecific level that is within humans has led to the emergence of humans as a plausible candidate for a new generation of emerging zoonotic viruses, rapidly adapting to survive. ${ }^{73}$

Moreover, with a large proportion of both symptomatic and asymptomatic population, it has been difficult to predict the exact pattern of this dynamic virus in COVID-19 prognosis. ${ }^{74}$ These novel strains like SARS-COV-2, thus arising, might be remaining asymptomatic in the new host population i.e. humans, for a certain period, after which clinical manifestations start developing in susceptible and immune-compromised individuals. Moreover, emerging data also suggests how viral interaction can alter the epigenetic landscape of the host and bring about subsequent changes in the immune response. Taking all these players into consideration, the modern face of viral infection in the human host is immensely complex. ${ }^{75-80}$ This further necessitates intricate surveillance of these mutationrecombination based evolution trends, occurring at an unimaginably fast rate and thus changing the preconceived time scales of evolution within these viral families. The presence of a wide range of asymptomatic population further complicates the situation. The concept of "mutation mist" or largely undetected silent mutation events, fine- tuning positive selection events in a newly acquired host range becomes a possibility in this regard. Now, that SARSCoV-2 is en route to becoming endemic amongst the human population in future, chances of favourable recombination events contributing to better survivability of virus in new hosts is high.

The bat population, which has been one of the most important reservoir hosts of coronaviruses, has been threatened in recent years by anthropogenic activities that have imbalanced the ecological homeostasis significantly, over the two decades. The virus might be on the verge of a bottleneck event that has forced it towards these host range shifts further enhanced by positive selection. This in consequence can propagate undetected mutational events in a large population and can bring about couple of waves during the pandemic of the same or mutated strain within the same host range that is intraspecifically.

With no species barrier in place, the molecular tinkering of an endemic viral species can give rise to more complicated strains, thereby further challenging an already bleak health system trying to understand the epidemiology of this contagious virus. The occurrence of this pandemic raises possibilities of more such outbreaks in the future due to causes encompassing epidemiological, ecological, environmental, socio-political factors etc. which is aptly depicted in Figure 3.

Special emphasis to understand the viral-host interaction, surveillance of viral-adaptability related changes at genomic level, and species-wide comparisons, including sampling of both symptomatic and asymptomatic population, can be crucial in developing effective long-lasting vaccines to eradicate the chances of future pandemics of such scale.

The world is interconnected more than ever and the human population is increasing in staggering numbers. Globalisation together with population explosion has taken a huge toll on the delicate ecological balance existing for millions of years. Rampant destruction of forests and other natural resources have threatened the existence of a wide variety of wildlife and has brought many to the brink of extinction. Moreover, an increased population density of humans has led to more interference and interaction with wildlife. This has exposed humans to strictly zoonotic infections and has also given rise to novel variations of pathogens capable of human to human transmission.

In nature, the ultimate evolutionary force is survival and propagation. With this point of view, the current pandemic can be evaluated in the light of viral evolution. Bats that serve as the main animal reservoir of the coronaviridae family have been threatened for quite some time due to the increasing man-animal conflict. Such conflicts have increased the chances of spillover events to an 
unprecedented level. This raises further concerns of a prospective "amplifying-host" in man. ${ }^{81}$ It is quite possible that the large asymptomatic population widely observable in the current pandemic, has a bigger role to play in the evolutionary course of the SARS-CoV-2.

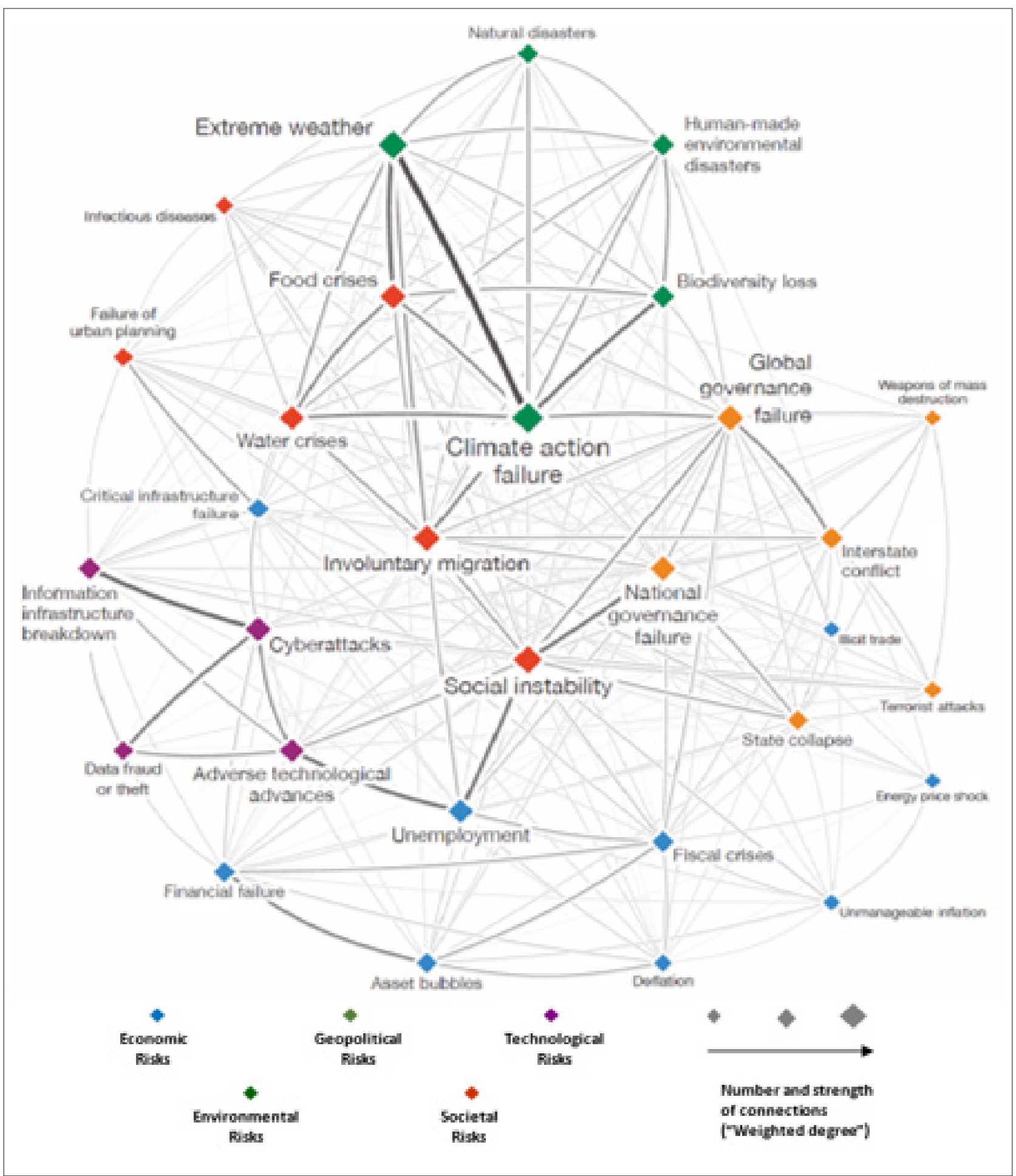

Figure 3.A Network depicting Interconnections of Various Plausible Eco-socio-political Factors in Global Phenomenon like a Pandemic ${ }^{82}$ 


\section{Conclusion}

As hypothesised in this article, a mutation mist among silent carriers prior to wide scale human to human transmission or viable virulent strains capable of it, might have been prevalent. Although, in evolutionary terms, the adaptability shown by the novel coronavirus has been extremely rapid, yet it cannot be ruled out that chance mutation and spike protein-ACE2 interactions have been occurring in the background. It is a matter of concern as to how exactly the species barrier has been breached and more importantly at what point in time. This also highlights the fact that such events are not exclusive and have been increasing in frequency over the past two decades as a combined effect of global population rise, changing climate and weather patterns, ecological imbalance and other contributing factors of rapid change. Another interesting thing to note is that the pandemic's global scale reflects the viral adaptability to a vast range of climate and geographical barriers. Moreover, its varied diagnostic characteristic from people to people, and differential modes of manifestation both in terms of symptoms and severity, underlies a possible relation of the SARS-CoV-2 adaptability to genetic as well as epigenetic makeup of the host. The argument gains favour that man is probably emerging as a new prospective amplifying host for the coronavirus. Further analysis and research are necessary to understand more about its virulence pattern, selection pressure, and also the question of rapid mutability in the face of existential threats arising in reservoir hosts due to anthropogenic causes.

It should ultimately be remembered that the existence of humans is highly interconnected to all other species inhabiting this ecological system, at a macro or micro level. Although the effect might not be direct, yet the slightest of changes in this balance will offset the entire system and increase the vulnerability of our species to threats otherwise masked by delicate barriers and niche segregation.

\section{Conflict of Interest: None}

\section{References}

1. Cui J, Li F, Shi ZL. Origin and evolution of pathogenic coronaviruses. Nat Rev Microbiol. 2019;17(3):181-92. [PubMed] [Google Scholar]

2. Hu B, Ge X, Wang LF, Shi Z. Bat origin of human coronaviruses. Virol J. 2015;12(1):221. [PubMed] [Google Scholar]

3. Vijaykrishna D, Smith GJD, Zhang JX, Peiris JSM, Chen $\mathrm{H}$, Guan Y. Evolutionary Insights into the Ecology of Coronaviruses. J Virol. 2007;81(15):4012-20. [PubMed] [Google Scholar]

4. Parvez MK, Parveen S. Evolution and Emergence of Pathogenic Viruses: Past, Present, and Future. Intervirology. 2017;60(1-2):1-7. [PubMed][Google
Scholar]

5. Johnson CK, Hitchens PL, Evans TS, Goldstein T, Thomas K, Clements A, Joly DO, Wolfe ND, Daszak P, Karesh WB, Mazet JK. Spillover and pandemic properties of zoonotic viruses with high host plasticity. Sci Rep. 2015;5(1):14830. [PubMed] [Google Scholar]

6. Warren CJ, Sawyer SL. How host genetics dictates successful viral zoonosis. PLoS Biol. 2019;17(4):e3000217. [PubMed] [Google Scholar]

7. Graham RL, Baric RS. Recombination, Reservoirs, and the Modular Spike: Mechanisms of Coronavirus CrossSpecies Transmission. J Virol. 2010;84(7):3134-46. [PubMed] [Google Scholar]

8. Ye ZW, Yuan S, Yuen KS, Fung SY, Chan CP, Jin DY. Zoonotic origins of human coronaviruses. Int J Biol Sci. 2020;16(10):1686-97. [PubMed] [Google Scholar]

9. Salata C, Calistri A, Parolin C, Palù G. Coronaviruses: a paradigm of new emerging zoonotic diseases. Pathog Dis. 2019;77(9). [PubMed] [Google Scholar]

10. John Hopkins Centre for System Science and Engineering. COVID-19 Data Repository System by the Centre for System Science and Engineering (CSSE) at John Hopkins University. 2021 Available at: https://ourworldindata. org/explorers/coronavirus-data-explorer?zoomToSelection=true\&time=2020-03-01..2021-04-30\&pickerSort=asc\&pickerMetric=location\&Metric=Confirmed+cases\&Interval=7-day+rolling+average\&Relative+to+Population=true \&Alig $n+o u t b r e a k s=-$ false\&country $=\sim$ OWID_WRL [accessed on: 30th April 2021]

11. John Hopkins Centre for System Science and Engineering. COVID-19 Data Repository System by the Centre for System Science and Engineering (CSSE) at John Hopkins University. 2021 Available at: https:// ourworldindata.org/explorers/coronavirus-data-explo rer?zoomToSelection=true \&time=2020-03-01 ..202104-30\&pickerSort=asc\&pickerMetric=location\&Metri $\mathrm{c}=$ Case+fatality+rate\&Interval=7-day+rolling+average \&Relative+to+Population=true\&Align+outbreaks=false \&country= OWID_WRL [accessed on: 30th April 2021

12. Zheng J. SARS-CoV-2: An Emerging Coronavirus that Causes a Global Threat. Int J Biol Sci. 2020;16(10):167885. [PubMed] [Google Scholar]

13. Guo YR, Cao QD, Hong ZS, Tan YY, Chen SD, Jin HJ, Tan KS, Wang DY, Yan Y. The origin, transmission and clinical therapies on coronavirus disease 2019 (COVID-19) outbreak - an update on the status. Mil Med Res. 2020;7(1):11. [PubMed] [Google Scholar]

14. Coronaviridae Study Group of the International Committee on Taxonomy of Viruses. The species Severe acute respiratory syndrome-related coronavirus: classifying 2019-nCoV and naming it SARS-CoV-2. Nat Microbiol. 2020;5(4):536-44. [PubMed] [Google 
Scholar]

15. Calisher $\mathrm{CH}$, Childs JE, Field HE, Holmes KV, Schountz T. Bats: Important Reservoir Hosts of Emerging Viruses. Clin Microbiol Rev. 2006;19(3):531-45. [PubMed] [Google Scholar]

16. Wu F, Zhao S, Yu B, Chen YM, Wang W, Song ZG, Hu Y, Tao ZW, Tian JH, Pei YY, Yuan ML, Zhang YL, Dai FH, Liu Y, Wang QM, Zheng JJ, Xu L, Holmes EC, Zhang YZ. A new coronavirus associated with human respiratory disease in China. Nature. 2020;579(7798):265-9. [PubMed] [Google Scholar]

17. Gorbalenya AE, Baker SC, Baric RS, de Groot RJ, Drosten C, Gulyaeva AA, Haagmans BL, Lauber C, Leontovich AM, Neuman BW, Penzar D, Perlman S, Poon LLM, Samborskiy D, Sidorov IA, Sola I, Ziebuhr J. Severe acute respiratory syndrome-related coronavirus: The species and its viruses - a statement of the Coronavirus Study Group. 2020. [Google Scholar]

18. Sahin AR, Erdogan A, Agaoglu PM, Dineri Y, Cakirci AY, Senel ME, Okyay RA, Tasdogan AM. 2019 Novel Coronavirus (COVID-19) Outbreak: A Review of the Current Literature. Eur J Med Oncol. 2020;4(1):1-7. [Google Scholar]

19. Seven days in medicine: 8-14 Jan 2020. BMJ. 2020;368:m132. [PubMed]

20. Yin Y, Wunderink RG. MERS, SARS and other coronaviruses as causes of pneumonia. Respirology. 2018;23(2):130-7. [PubMed] [Google Scholar]

21. Prentice E, Jerome WG, Yoshimori T, Mizushima N, Denison MR. Coronavirus Replication Complex Formation Utilizes Components of Cellular Autophagy. J Biol Chem. 2004;279(11):10136-41. [PubMed] [Google Scholar]

22. Fung TS, Liu DX. Human Coronavirus: Host-Pathogen Interaction. Annu Rev Microbiol. 2019;73(1):529-57. [PubMed] [Google Scholar]

23. Sironi M, Hasnain SE, Rosenthal B, Phan T, Luciani $F$, Shaw MA, Sallum MA, Mirhashemi ME, Morand S, González-Candelas F, Editors of Infection, Genetics and Evolution. SARS-CoV-2 and COVID-19: A genetic, epidemiological, and evolutionary perspective. Infect Genet Evol. 2020;84:104384. [PubMed] [Google Scholar]

24. Brufsky A. Distinct viral clades of SARS-CoV-2: Implications for modeling of viral spread. J Med Virol. 2020;92(9):1386-90. [PubMed] [Google Scholar]

25. Laha S, Chakraborty J, Das S, Manna SK, Biswas S, Chatterjee R. Characterizations of SARS-CoV-2 mutational profile, spike protein stability and viral transmission. Infect Genet Evol. 2020;85:104445. [PubMed] [Google Scholar]

26. Li F. Structure, Function, and Evolution of Coronavirus Spike Proteins. Annu Rev Virol. 2016;3(1):237-61.
[PubMed] [Google Scholar]

27. Artika IM, Dewantari AK, Wiyatno A. Molecular biology of coronaviruses: current knowledge. Heliyon. 2020;6(8):e04743. [PubMed] [Google Scholar]

28. Li W, Zhang C, Sui J, Kuhn JH, Moore MJ, Luo S, Wong SK, Huang IC, Xu K, Vasilieva N, Murakami A, He Y, Marasco WA, Guan Y, Choe H, Farzan M. Receptor and viral determinants of SARS-coronavirus adaptation to human ACE2. EMBO J. 2005;24(8):1634-43. [PubMed] [Google Scholar]

29. Gussow AB, Auslander N, Faure G, Wolf YI, Zhang F, Koonin EV. Genomic determinants of pathogenicity in SARS-CoV-2 and other human coronaviruses. Proc Nat Acad Sci. 2020;117(26):15193-9.[PubMed] [Google Scholar]

30. Meirson T, Bomze D, Markel G. Structural basis of SARSCoV-2 spike protein induced by ACE2. Bioinformatics. 2021;37(7):929-36. [PubMed] [Google Scholar]

31. Yan R, Zhang Y, Li Y, Xia L, Guo Y, Zhou Q. Structural basis for the recognition of SARS-CoV-2 by full-length human ACE2. Science. 2020;367(6485):1444-8. [PubMed] [Google Scholar]

32. Brielle ES, Schneidman-Duhovny D, Linial M. The SARSCoV-2 Exerts a Distinctive Strategy for Interacting with the ACE2 Human Receptor. Viruses. 2020;12(5):497. [PubMed] [Google Scholar]

33. Matyášek R, Kovařík A. Mutation Patterns of Human SARS-CoV-2 and Bat RaTG13 Coronavirus Genomes Are Strongly Biased Towards C $>U$ Transitions, Indicating Rapid Evolution in Their Hosts. Genes. 2020;11(7):761. [PubMed] [Google Scholar]

34. Lucas M, Karrer U, Lucas A, Klenerman P. Viral escape mechanisms - escapology taught by viruses. Int J Exp Pathol. 2001;82(5):269-86. [PubMed] [Google Scholar]

35. Subudhi S, Rapin N, Misra V. Immune System Modulation and Viral Persistence in Bats: Understanding Viral Spillover. Viruses. 2019;11(2):192. [PubMed] [Google Scholar]

36. Leeks A, Segredo-Otero EA, Sanjuán R, West SA. Beneficial coinfection can promote within-host viral diversity. Virus Evol. 2018;4(2):vey028. [PubMed] [Google Scholar]

37. Parrish CR, Holmes EC, Morens DM, Park EC, Burke DS, Calisher CH, Laughlin CA, Saif LJ, Daszak P. Cross-Species Virus Transmission and the Emergence of New Epidemic Diseases. Microbiol Mol Biol Rev. 2008;72(3):457-70. [PubMed] [Google Scholar]

38. DeFilippis VR, Villarreal LP. An Introduction to the Evolutionary Ecology of Viruses. Viral Ecol . 2000:125208. [Google Scholar]

39. Fu J, Zhou B, Zhang L, Balaji KS, Wei C, Liu X, Chen H, Peng J, Fu J. Expressions and significances of the angiotensinconverting enzyme 2 gene, the receptor of SARS-CoV-2 
for COVID-19. Mol Biol Rep. 2020;47(6):4383-92. [PubMed] [Google Scholar]

40. Hofmann H, Simmons G, Rennekamp AJ, Chaipan C, Gramberg T, Heck E, Geier M, Wegele A, Marzi A, Bates $P$, Pöhlmann S. Highly Conserved Regions within the Spike Proteins of Human Coronaviruses 229E and NL63 Determine Recognition of Their Respective Cellular Receptors. J Virol. 2006;80(17):8639-52. [PubMed] [Google Scholar]

41. Walls AC, Park YJ, Tortorici MA, Wall A, McGuire AT, Veesler D. Structure, Function, and Antigenicity of the SARS-CoV-2 Spike Glycoprotein. Cell. 2020;181(2):28192.e6. [PubMed] [Google Scholar]

42. Demogines A, Abraham J, Choe H, Farzan M, Sawyer SL. Dual Host-Virus Arms Races Shape an Essential Housekeeping Protein. PLoS Biol. 2013;11(5):e1001571. [PubMed] [Google Scholar]

43. Forni D, Cagliani R, Clerici M, Sironi M. Molecular Evolution of Human Coronavirus Genomes. Trends Microbiol. 2017;25(1):35-48. [PubMed] [Google Scholar]

44. Almand EA, Moore MD, Jaykus LA. Virus-Bacteria Interactions: An Emerging Topic in Human Infection. Viruses. 2017;9(3):58. [PubMed] [Google Scholar]

45. Demogines A, Farzan M, Sawyer SL. Evidence for ACE2-Utilizing Coronaviruses (CoVs) Related to Severe Acute Respiratory Syndrome CoV in Bats. J Virol. 2012;86(11):6350-3. [PubMed] [Google Scholar]

46. Lu G, Wang $Q$, Gao GF. Bat-to-human: spike features determining 'host jump' of coronaviruses SARSCoV, MERS-CoV, and beyond. Trends Microbiol. 2015;23(8):468-78. [PubMed] [Google Scholar]

47. Tan Y, Schneider T, Leong M, Aravind L, Zhang D. Novel Immunoglobulin Domain Proteins Provide Insights into Evolution and Pathogenesis of SARS-CoV-2-Related Viruses. mBio. 2020;11(3):e00760-20. [PubMed] [Google Scholar]

48. Lau SKP, Feng $Y$, Chen $H$, Luk HKH, Yang WH, Li KSM, Zhang YZ, Huang $Y$, Song ZZ, Chow WN, Fan RYY, Ahmed SS, Yeung HC, Lam CSF, Cai JP, Wong SSY, Chan JFW, Yuen KY, Zhang HL, Woo PCY. Severe Acute Respiratory Syndrome (SARS) Coronavirus ORF8 Protein Is Acquired from SARS-Related Coronavirus from Greater Horseshoe Bats through Recombination. J Virol. 2015;89(20):10532-47. [PubMed] [Google Scholar]

49. Ceraolo C, Giorgi FM. Genomic variance of the 2019nCoV coronavirus. J Med Virol. 2020;92(5):522-8. [PubMed] [Google Scholar]

50. Kane M, Golovkina T. Common Threads in Persistent Viral Infections. J Virol. 2010;84(9):4116-23. [PubMed] [Google Scholar]

51. Das P, Choudhuri T. Decoding the global outbreak of COVID-19: the nature is behind the scene. Virus disease.
2020;31(2):106-12. [PubMed] [Google Scholar]

52. Virology: Viruses switch hosts to evolve. Nature. 2017;543(7646):466. [PubMed]

53. Domingo E, Sheldon J, Perales C. Viral Quasispecies Evolution. Microbiol Mol Biol Rev. 2012;76(2):159-216. [PubMed] [Google Scholar]

54. Bhattacharya S, Sinha S, Tilak R, Mardihusodo SJ. The relationship between bats and human coronavirus: An exploratory review. J Health Soc Sci. 2020;5(2):219-30. [Google Scholar]

55. Maganga GD, Pinto A, Mombo IM, Madjitobaye M, Beyeme AMM, Boundenga L, ArGouilh M, N'Dilimabaka N, Drexler JF, Drosten C, Leroy EM. Genetic diversity and ecology of coronaviruses hosted by cave-dwelling bats in Gabon. Sci Rep. 2020;10(1):7314. [PubMed] [Google Scholar]

56. Wang LF, Shi Z, Zhang S, Field H, Daszak P, Eaton BT. Review of Bats and SARS. Emerg Infect Dis. 2006;12(12):1834-40. [PubMed] [Google Scholar]

57. Decaro N, Lorusso A. Novel human coronavirus (SARS-CoV-2): A lesson from animal coronaviruses. Vet Microbiol. 2020;244:108693. [PubMed] [Google Scholar]

58. Raoult D, Zumla A, Locatelli F, Ippolito G, Kroemer G. Coronavirus infections: Epidemiological, clinical and immunological features and hypotheses. Cell Stress. 2020;4(4):66-75. [PubMed] [Google Scholar]

59. Tang X, Li G, Vasilakis N, Zhang Y, Shi Z, Zhong Y, Wang LF, Zhang S. Differential Stepwise Evolution of SARS Coronavirus Functional Proteins in Different Host Species. BMC Evol Biol. 2009;9(1):52. [PubMed] [Google Scholar]

60. Tang X, Wu C, Li X, Song Y, Yao X, Wu X, Duan Y, Zhang H, Wang Y, Qian Z, Cui J, Lu J. On the origin and continuing evolution of SARS-CoV-2. Nat Sc Rev. 2020;7(6):101223. [Google Scholar]

61. Wertheim JO, Chu DKW, Peiris JSM, Pond SLK, Poon LLM. A Case for the Ancient Origin of Coronaviruses. J Virol. 2013;87(12):7039-45. [PubMed] [Google Scholar]

62. Zhou $P$, Yang $X L$, Wang $X G$, Hu B, Zhang L, Zhang W, Si HR, Zhu Y, Li B, Huang CL, Chen HD, Chen J, Luo Y, Guo $H$, Jiang RD, Liu MQ, Chen Y, Shen XR, Wang X, Zheng XS, Zhao K, Chen QJ, Deng F, Liu LL, Yan B, Zhan FX, Wang YY, Xiao GF, Shi ZL. A pneumonia outbreak associated with a new coronavirus of probable bat origin. Nature. 2020;579(7798):270-3. [PubMed] [Google Scholar]

63. Hu D, Zhu C, Ai L, He T, Wang Y, Ye F, Yang L, Ding C, Zhu X, Lv R, Zhu J, Hassan B, Feng Y, Tan W, Wang C. Genomic characterization and infectivity of a novel SARS-like coronavirus in Chinese bats. Emerg Microbes Infect. 2018;7(1):154. [PubMed] [Google Scholar]

64. Grimmond S. Urbanization and global environmental change: local effects of urban warming. Geo J. 
2007;173(1):83-8. [Google Scholar]

65. Woo PC, Lau SK, Yuen KY. Infectious diseases emerging from Chinese wet-markets: zoonotic origins of severe respiratory viral infections. Curr Opin Infect Dis. 2006;19(5):401-7. [PubMed] [Google Scholar]

66. Biswas A, Bhattacharjee U, Chakrabarti AK, Tewari DN, Banu H, Dutta S. Emergence of Novel Coronavirus and COVID-19: whether to stay or die out? Crit Rev Microbiol. 2020;46(2):182-93. [PubMed] [Google Scholar]

67. Chatterjee R, Bhattacharya S. Could Novel Corona Virus (SARS-CoV-2) be the evolving face of a new generation of genetically complex epidemiological challenge? Malay J Med Res. 2020;4(2):42-45. [Google Scholar]

68. Frenk J, Gómez-Dantés O, Knaul FM. Globalization and Infectious Diseases. Infect Dis Clin North Am. 2011;25(3):593-9. [PubMed] [Google Scholar]

69. Lowen AC. It's in the mix: Reassortment of segmented viral genomes. PLoS Pathog. 2018;14(9):e1007200. [PubMed] [Google Scholar]

70. Sanjuán R, Domingo-Calap P. Mechanisms of viral mutation. Cell Mol Life Sci. 2016;73(23):4433-48. [PubMed] [Google Scholar]

71. Pachetti M, Marini B, Benedetti F, Giudici F, Mauro E, Storici P, Masciovecchio C, Angeletti S, Ciccozzi M, Gallo RC, Zella D, Ippodrino R. Emerging SARS-CoV-2 mutation hot spots include a novel RNA-dependent-RNA polymerase variant. J Transl Med. 2020;18(1):179. [PubMed] [Google Scholar]

72. Duffy $S$. Why are RNA virus mutation rates so damn high? PLoS Biol. 2018;16(8):e3000003. [PubMed] [Google Scholar]

73. Kobayashi N. Impact of Emerging, Re-Emerging and Zoonotic Viral Infectious Diseases, in a Virologist's Perspective. Open Virol J. 2018;12(1):131-3. [PubMed] [Google Scholar]

74. Savvides C, Siegel R. Asymptomatic and presymptomatic transmission of SARS-CoV-2: A systematic review. medRxiv. 2020. [PubMed] [Google Scholar]

75. Andersen KG, Rambaut A, Lipkin WI, Holmes EC, Garry RF. The proximal origin of SARS-CoV-2. Nat Med. 2020;26(4):450-2. [PubMed] [Google Scholar]

76. Zhao Z, Li H, Wu X, Zhong Y, Zhang K, Zhang YP, Boerwinkle E, Fu YX.Moderate mutation rate in the SARS coronavirus genome and its implications. BMC Evol Biol. 2004;4(1):21. [PubMed] [Google Scholar]

77. Schäfer A, Baric RS. Epigenetic Landscape during Coronavirus Infection. Pathogens. 2017;6(1):8. [PubMed] [Google Scholar]

78. Lu R, Zhao X, Li J, Niu P, Yang B, Wu H, Wang W, Song $H$, Huang B, Zhu N, Bi Y, Ma X, Zhan F, Wang L, Hu T, Zhou H, Hu Z, Zhou W, Zhao L, Chen J, Meng Y, Wang J, Lin Y, Yuan J, Xie Z, Ma J, Liu WJ, Wang D, Xu W,
Holmes EC, Gao GF, Wu G, Chen W, Shi W, Tan W. Genomic characterisation and epidemiology of 2019 novel coronavirus: implications for virus origins and receptor binding. Lancet. 2020;395(10224):565-74. [PubMed] [Google Scholar]

79. Darbeheshti F, Rezaei N. Genetic predisposition models to COVID-19 infection. Med Hypotheses. 2020;142:109818. [PubMed] [Google Scholar]

80. Tan J, Liu S, Zhuang L, Chen L, Dong M, Zhang J, Xin Y. Transmission and clinical characteristics of asymptomatic patients with SARS-CoV-2 infection. Fut Virol. 2020;15(6):373-80. [Google Scholar]

81. Bhattacharya S, Basu P, Poddar S. Changing epidemiology of SARS-CoV in the context of COVID-19 pandemic. J Prev Med Hyg. 2020;61(2):E130-E136. Published 2020 Jul 4. doi:10.15167/2421-4248/jpmh2020.61.2.1541

82. World Economic Forum. The global Risk Report 2020. 2020 Available at: https://www.weforum.org/reports/ the-global-risks-report-2020 [accessed on: 18th March 2021] 